\title{
Masculinidades coloniais no fim do império português: o a taque à Vila Alice, Luanda $1975^{1}$
}

Resumo: Este trabalho reflete sobre o Ataque à Vila Alice, ataque conduzido em Luanda, Angola, pelas Forças Armadas Portuguesas no dia 27 de Julho de 1975 contra o MPLA, Movimento Popular de Libertação de Angola. A reflexão enquadra esta ação militar num quadro de violência colonial ligada a arquétipos predominantemente masculinos e a paradigmas de masculinidades transversais a hierarquias de raça e género destinadas a humilhar e inferiorizar os africanos. Do ponto de vista da História e da Memória, no que diz respeito à análise de factos apurados na investigação historiográfica são confrontadas fontes escritas versus fontes orais. $\mathrm{Na}$ análise crítica e reflexiva, o trabalho centra-se fundamentalmente na desconstrução racial e genderizada ${ }^{3}$ do Ataque.

Palavras-chave: memória, história oral, testemunhos, racismo, género, masculinidades, colonialismo português

Abstract: This study reflects upon the Attack on Vila Alice, an attack launched in Luanda, Angola, by the Portuguese Armed Forces on 27 July 1975 against the MPLA - the Popular Movement for the Liberation of Angola. The military strike will be looked at from within the framework of colonial violence linked to the predominantly masculine archetypes and the transversal paradigms of masculinity evident throughout the racial and gender hierarchies, and aimed at humiliating and belittling the Africans. From the perspective of History and Memory, where the analysis of facts has been made in historiographical research, written sources are compared with oral sources. The ensuing critical and reflexive analysis will focus mainly on the racial and gendered deconstruction

1 Uma primeira versão deste artigo, intitulada Building Violence: Portugal responsibility in the failed Political Transition in Angola, in 1974-75 foi apresentada no congresso anual da ASA (2006), African Studies Association em San Francisco, USA, integrada no painel da LASO (Lusophone African Studies Organization) sobre Political Transitions: Democracy, State Formation, and Violence in Colonial and Postcolonial Lusophone Africa.

2 Pesquisadora membro do CRIA, ISCTE-IUL, Lisboa, Portugal e NUER, UFSC, Florianópolis, Brasil

3 Gendered 
Sankofa. Revista de História da África e de Estudos da Diáspora Africana Ano VI, NXII,

Dezembro/2013

of the Attack.

Keywords: memory, oral history, testimonies, racism, gender, masculinities, Portuguese colonialism

\section{Introdução}

Este artigo é resultado de uma reflexão elaborada na dupla condição de cientista social e sujeito da história. Decidi debruçar-me sobre o Ataque à Vila Alice, levada pela inusitada circunstância de ter estado diretamente envolvida no confronto que opôs as Forças Armadas Portuguesas às FAPLA, Forças Armadas Populares de Libertação de Angola do MPLA e com a intenção de entender as razões do Ataque. Como refere Yussuf Adam, $A$ minha análise abrange um período e um espaço geográfico em que [...] vivi. É o meu chão (2005:60).

Quando iniciei a pesquisa bibliográfica fui confrontada com a ausência de estudos académicos sobre este recorte histórico e não estava à espera de encontrar versões escritas antagónicas em livros de memórias de antigos combatentes, narrativas biográficas, relatos históricos ou artigos de jornais, versões que produziram em mim um profundo estranhamento na medida em que não coincidiam com as minhas memórias. $\mathrm{Na}$ esteira de Beatriz Sarlo (2007), quando se fala de passado, a História tem dificuldade em dar credibilidade à Memória e esta, por sua vez, reivindica o direito de recordar quando se trata de reconstituições históricas, este desencontro cria alguns conflitos epistémicos entre História e Memória.

Como mulher e antropóloga enunciadora deste artigo, o recurso à História como ferramenta de análise é resultado da convergência que existe entre a Antropologia e a História e do encontro que historiadores e antropólogos protagonizam no campo da memória coletiva (Goff, 2006: 468) e da História Oral.

Mais de trinta anos depois do Ataque à Vila Alice questionava-me sobre o que teria conduzido as FAP $^{1}$ no dia 27 de Julho de 1975, no fim do Império Colonial e nos últimos meses da presença portuguesa em Angola, a tomarem a iniciativa de atacar um bairro

1 Após a bibliografia, segue a relação de siglas e abreviaturas. 
residencial de Luanda, a Vila Alice, onde, dispersas por várias moradias disseminadas num quarteirão habitado pela classe média luandense se encontravam várias estruturas dirigentes do MPLA, nomeadamente a Delegação Oficial do movimento e o COL, Comando Operacional das suas forças armadas. Pode-se dizer que a Vila Alice era o centro do MPLA em Luanda e atacar as estruturas do MPLA na Vila Alice significava atingir a coluna vertebral do Movimento.

A derradeira ofensiva militar portuguesa em África, depois de séculos de ocupação territorial, ficou marcada por um forte simbolismo, representou o canto fúnebre do Império Colonial Português na hora da partida. No dia 11 de Novembro de 1975, encontrava-me presente na praça onde foi proclamada a independência de Angola e além da grande emoção que foi testemunhar o nascimento de um novo país, da nação pela qual tinha lutado, senti-me como se estivesse a "fechar a porta" do Império.

\section{O Problema da Ilusão Biográfica ${ }^{2}$}

Para refletir sobre o Ataque à Vila Alice e escrever na primeira pessoa, por razões éticas, sinto-me compelida como mulher, branca e europeia a definir o meu lugar de enunciação e situar-me no processo de descolonização ${ }^{3}$ em Angola, em virtude de entender que nenhum testemunho é independente do contexto em que é produzido e porque, como nos diz a teórica feminista da condição mestiça, Gloria Anzaldúa, falamos sempre a partir de um determinado lugar situado nas estruturas do poder (Anzaldúa, 1983). ${ }^{4}$

Pertenço a uma minoria da comunidade portuguesa residente em Angola, que lutou pela independência do país ao lado MPLA. Pode parecer que o MPLA não era o lugar natural de pertencimento de uma filha do Império, mas para a autora deste texto, essa opção, foi feita de uma maneira muito espontânea e solidária. Confrontada com a desigualdade e as humilhações que os angolanos sofriam durante a ocupação colonial e refém da má consciência que a dominação produzia, assumi como meus os ressentimentos e dores dos angolanos. Rebelde e embalada por utopias poderosas, como o discurso

2 Título de um capítulo de um livro de Pierre Bourdieu, Razões Práticas: sobre a Teoria da Acção, Oeiras, Celta Editora, 1997

3 Descolonização o processo de transição que conduziu ao fim do Império português em África.

4 Para Donna Haraway o conhecimento também é sempre situado (Haraway 1988) 
internacionalista da revolução cubana e a ideologia libertária de Che Guevara, mudar para o outro lado da barricada e lutar ao lado do MPLA pareceu-me, nos anos setenta, uma opção carregada de sentidos para quem aspirava à ação. A escolha do MPLA ficou a dever-se ao ter sido sensível, ao capital simbólico de esperança que este Movimento acumulou durante a Luta de Libertação nacional, ao seu discurso internacionalista e antirracista, e ter sido o único movimento que, na época, identificava como moderno e progressista.

Nos últimos anos da guerra, guerra que os portugueses chamam de Colonial e os angolanos de Luta de Libertação, os ventos da história e das independências africanas sopravam contra Portugal, o país era condenado internacionalmente pela ocupação colonial e a ditadura projetava Portugal no mundo como um país periférico, subalterno e atrasado. Neste cenário, ainda hoje me parece muito natural o caminho que percorri apesar de sectores mais ultranacionalistas e "ultramarinistas" em Portugal me acusarem de traição à pátria (Mata, 2011).

Aos dezanove anos, em 1973, tomei a iniciativa de aderir ao MPLA ${ }^{5}$ e depois do 25 de Abril fui simultaneamente instrutora política no CIR Hoji Ya Henda, Centro de Instrução Revolucionária e instruenda militar tendo completado a instrução armada juntamente com o malogrado Destacamento Feminino ${ }^{6}$ das FAPLA o que me coloca numa posição pouco comum como sujeito da guerra ou seja como agente da guerra no feminino. Num mundo em que geralmente os homens fazem a guerra e as mulheres são atiradas para lugares estereotipados de vítimas ou essencializadas de pacifistas, isto quando não são completamente invisibilizadas, colocar-me no sistema da guerra e assumir-me como agente da violência vai permitir uma análise genderizada e racializada do Ataque, isto é, vai permitir responder à pergunta: - como reagiram os militares portugueses a uma jovem mulher branca fardada durante o Ataque?

Quando iniciei a pesquisa fui confrontada, como já foi referido, com fontes escritas contraditórias que serão identificadas mais à frente, e que não correspondiam à memória que tinha dos acontecimentos. No entanto, no contexto da historiografia ocidental a fonte escrita é sempre um documento privilegiado que produz um regime de verdade. Ousar

5 A adesão foi feita através da Delegação do MPLA na Tanzânia, confirmada pelo atual dirigente do Bureau Politico, França Van-dúnem (Mbinda).

6 Malogrado porque a comandante do Destacamento Feminino, Virinha, Elvira Maria da Conceição a comissária política, Nandi, Fernanda Delfim e chefe de operações, Boneca (nome de guerra) foram fuziladas pelo MPLA no morticínio que se seguiu à insurreição armada do 27 de Maio de 1977. 
confrontar fontes escritas com uma narrativa baseada num testemunho pessoal, pareceu-me desde o início, além da Ilusão Biográfica, ${ }^{7}$ suscetível de pouca credibilidade em termos de um trabalho com aspirações a ser científico e a ser elaborado segundo as regras da arte praticadas pela história e pelas ciências sociais. Depois de Rousseau e Rossi o passado é “concebido, 'reconstruído' e organizado sobre a base de uma coerência imaginária" (Rossi, 2003:87-8) o que pode ser problemático para a historiografia.

À versão oficial do MPLA, enunciada na literatura e na imprensa, contrapunha-se a memória pessoal de quem tinha estado no terreno e tinha sido testemunha de uma das versões da história. Como sujeito, a pretensão e tentação de contribuir para clarificar um facto histórico era grande mas, como analista, o terreno apresentava-se minado na medida em que não é objetivo da investigação histórica validar factos mas sim entender as diferentes versões da História.

Como mulher e guerrilheira o terreno ainda se configurava mais pantanoso porque as forças militares são instituições patriarcais, os homens têm o monopólio do poder militar e neste cenário as mulheres não são percebidas como agentes sociais e tradicionalmente élhes recusado o papel de atores que lutaram e pertenceram a exércitos. Hoje em dia sabemos que a democratização dos atores da História (através da guinada subjetiva da História) e a autoridade com a qual a História Oral é investida deram a palavra ao indivíduo que tem que encontrar o seu lugar na história coletiva; ele retorna a si mesmo para definir suas próprias marcas e fazer a sua própria história. (Delory-Momberger, 2006:106)

Para encontrar o meu lugar neste fragmento da história foi necessário equacionar algumas questões metodológicas: (1) como sair do velho porém atuante paradigma que privilegia fontes escritas em detrimento das fontes orais e da memória individual? (2) como refletir sobre um acontecimento do qual também fui protagonista? (3) como me situar no campo da investigação histórica e ao mesmo tempo ser uma "fonte viva"?

Uma das opções metodológicas, em termos da historiografia, foi possibilitar que as diferentes versões dialoguem umas com as outras na tentativa de ultrapassar a ambiguidade e a subjetividade de um trabalho que se quer historiográfico. A transcrição das diferentes

7 as histórias de vida não podem ser desvinculadas do conjunto de acontecimentos que fazem parte da trajetória do sujeito. 
fontes escritas e o registo das fontes orais, incluindo a da autora criam um corpus de testemunhos abrangente aos dois lados do conflito que permite refletir e confrontar fontes. A reflexão do Ataque é feita, no entanto, sem tentar escamotear que é uma sensibilidade carregada de subjetividade de quem esteve envolvida no terreno e numa ação militar do outro lado da barricada. Quanto à análise crítica acabou por se revelar um desafio transversal a várias áreas do conhecimento através das lentes da teoria crítica feminista, dos estudos de género e dos estudos pós-coloniais. ${ }^{8}$

\section{Breve Genealogia da violência}

\section{- Do 25 de Abril de 1974 ao Ataque à Vila Alice}

1. O historiador Mabéko-Tali na obra "O MPLA perante si próprio, II" considera que a sociedade colonial em 1974 foi apanhada de surpresa pela revolução do 25 de Abril " (2001:24). Para este analista, as duas comunidades, africana e portuguesa, viviam em universos culturais e sociais diferentes e com identidades distintas, por isso as mudanças que o golpe de estado do MFA introduziu na agenda política da época não foram percecionadas da mesma maneira por colonizados e colonizadores. (2001:30-31). Insistindo no que separava os africanos dos colonos, Mabéko-Tali refere que as manifestações na capital mergulharam num ciclo de inaudita violência as duas comunidades [branca e negra] e que os ódios acumulados mostraram, durante longas semanas, toda a sua medida. (2001:32) A partir de Julho, a situação agravou-se e degenerou em autênticos confrontos raciais na capital provocados, principalmente pelos brancos de baixa renda que foram expulsos dos musseques. (Tali 2001:33)

2. A comunidade branca entrincheirada numa supremacia política e socioeconómica não percebeu o sentido do golpe de estado em Lisboa e em Angola nunca valorizou as estratégias de resistência que a sociedade africana criou para reagir à dominação e ocupação portuguesa. Não percebeu que as guerras de resistência tinham entrado pelo séc. $\mathrm{XX}$, não percebeu o papel das igrejas sobretudo a protestante, do associativismo, da literatura, da música, da cultura e a força da não-resignação dos angolanos. Também não

8 É de notar que apesar da autora ter estado ao lado dos angolanos como sujeito da história, este trabalho em termos da historiografia não teve como objetivo investigar o ponto de vista ou os atores africanos. 
percebeu o papel dos Movimentos Nacionalistas e a pressão das Lutas de Libertação e durante quatro longos meses após o 25 de Abril reagiu violentamente, envolvendo-se em conflitos de matriz racial liderados sobretudo por taxistas e comerciantes brancos, como já foi dito.

3. O MFA, não pensou em incluir no seu programa o reconhecimento do direito das colónias portuguesas à autodeterminação e independência já reconhecido pela Carta das Nações Unidas e pela Assembleia Geral da ONU. Durante três meses até à promulgação da lei 7/74, de 27 de Julho que viria a permitir que a descolonização se fizesse por negociação direta com os movimentos de libertação, a situação, neste período degradou-se política e militarmente. Enquanto em Portugal o povo gritava "nem mais um soldado para as colónias”, nas colónias os militares das FAP recusavam-se a lutar por uma "guerra" que já não era deles e os movimentos de libertação ansiosos por negociar numa posição de força aumentavam o tom das suas exigências.

4. O 25 de Abril criou novas dinâmicas políticas e a pressão dos movimentos de libertação MPLA, FNLA e UNITA sobre o MFA, ao defenderem o princípio da legitimação política revolucionária através da luta armada, afastou todos os outros grupos do processo de transferência do poder, ratificado pelos Acordos de Alvor assinado a 15 de Janeiro de 1975 (cf Tali 2001:37-45)

5. Heimer no seu livro O Processo de Descolonização de Angola, 1974-1976, defende que apesar da integração gradual, supervisionada pelas forças portuguesas das forças militares dos três movimentos num exército [único], isso não impediu que a competição entre os três movimentos assumisse formas outras que não políticas (1980:67). Depois dos conflitos entre os africanos e a comunidade branca, numa segunda fase, a luta pela hegemonia militar foi protagonizada pelos três movimentos numa estratégia de exclusão mútua (Tali 2001,19) ${ }^{9}$ e num contexto de polarização mundial dependente da Guerra Fria. A 14 de Fevereiro a delegação do dissidente Chipenda, líder da Revolta de

9 A "estratégia de exclusão mútua" que Tali refere teve origem no início da Luta de Libertação, 1961, com os três movimentos, MPLA, FNLA e mais tarde UNITA (1966) a disputarem projetos políticos nacionalistas conflituantes e a lutarem entre si. 
$\operatorname{Leste}^{10}$ foi atacada pelo MPLA. A competição política pacífica até ao 11 de Novembro, data acordada para a independência colapsou completamente e o caminho para a independência foi feito debaixo de uma confrontação militar generalizada. A comunidade branca, pressionada pelo medo e insegurança dos conflitos armados entre os três Movimentos de Libertação ${ }^{11}$ abandonou em massa Angola.

\section{A batalha por Luanda e o ataque às Vila Alice - as fontes escritas}

Em 9 de Julho, o MPLA lançou a chamada "Batalha por Luanda" para vencer militarmente a FNLA e UNITA sob o olhar das Forças Armadas Portuguesas. As lutas políticas e militares em Angola decidiam-se em Luanda e por meio de uma ação combinada das suas "forças regulares, FAPLA [...] e das milícias do Poder Popular, o MPLA dominou a maior parte da capital ao fim de uma semana”. (Heimer 1978:81)

A "Batalha por Luanda" uma verdadeira luta pelo poder, marcou o início da guerra civil pós-colonial em Angola, ainda sob soberania portuguesa. O General Silva Cardoso, alto-comissário $^{12}$ na altura, face ao ciclo de violência que se instalou em Luanda entrincheirou-se na neutralidade ativa não envolvendo as FAP nos confrontos. ${ }^{13}$

Num comentário carregado de desespero e registado a 14 de Julho de 1975 no seu livro, Angola, Anatomia de uma tragédia, o General Silva Cardoso escreveu:

Que faço aqui? Há três dias que Luanda está a ferro e fogo. [...] Creio que a

10 'Revolta de Leste', dissidência interna no MPLA na $3^{\text {a }}$ Região Militar que contestava a liderança do presidente Agostinho Neto, comandada por Daniel Chipenda em 1973 e que reunia grande parte dos guerrilheiros da Frente Leste. No início de 1975, Daniel Chipenda tinha uma Delegação em Luanda que foi atacada a 14 de Fevereiro pelas forças das FAPLA/MPLA lideradas pelo comandante Valódia, Joaquim Domingos Augusto, morto no ataque.

11 Fanon em "Os Condenados da Terra" defende que não é possível que colonos e colonizados vivam em paz num mundo novo e para o "colono" logo que o contexto colonial desaparece, não tem mais interesse em ficar, em coexistir (2006[1961]:62)

12 O mais elevado representante da soberania portuguesa em Angola.

13 Norrie Macqueen analisa o Ataque no quadro de self-defence e peacekeeping operations e defende: it's difficult to see how the Portuguese doctrine of "active neutrality" in Angola would have prevented punitive action against the MPLA. Even the most minimalist rules of engagement for peacekeeping operations give a high priority to freedom of movement and the inherent right to self-defence. Both of these lay at the centre of the Vila Alice affair. Norrie Macqueen, University of Dundee, 29 December 2005, HLUSO-AFRICA, RE: Query: Attack at Vila Alice, 1975 
Sankofa. Revista de História da África e de Estudos da Diáspora Africana Ano VI, NXII,

Dezembro/2013

minha missão chegou ao fim. O Acordo do Alvor onde tinha sido definida acabou. Julgo mesmo que nunca chegou a existir para as outras partes. [...] Vou [...] pedir a minha exoneração. [...] Mas antes da partida ainda tive de resolver um incidente de alguma gravidade. No dia 26, já tarde, talvez pouco antes da meia-noite, fui informado que uma patrulha do MPLA tinha intercetado um jipe das FAP que transportava um sargento e o respetivo condutor. Apesar de estarem fardados, foram obrigados a identificar-se e depois deixados seguir. No entanto o impensável aconteceu: os elementos das FAPLA alvejaram os nossos militares pelas costas e feriram gravemente o sargento. De imediato reuni os meus comandantes, o Almendra e CCPA. Feita a análise do que tinha ocorrido foi decidido, sem vozes discordantes, que no dia seguinte de manhã cedo o Almendra montaria uma operação para que fossem entregues os responsáveis pelo crime praticado e que esta entrega far-se-ia a bem ou a mal. A operação foi montada, os homens não foram entregues e as NT entraram em ação... (2000: 648-656), (sublinhado da autora).

\section{Guerra de memórias, os "agentes infiltrados"}

Apesar do Gen. Silva Cardoso identificar no seu livro uma patrulha das FAPLA como responsável do incidente que vitimou o oficial português, todas as narrativas posteriores sobre o incidente defendem que não se tratou de uma patrulha das FAPLA mas sim de agentes infiltrados nas FAPLA. Como acontece em muitas situações militares as declarações das fontes são contraditórias. Competindo no terreno multiplicam-se em declarações com o objetivo de ganhar espaço político. A historiadora Christine Messiant estava certa quando enunciou que Em Angola, até o passado é imprevisivel... (1997:803).

Uma notícia de grande destaque na primeira página do Jornal República, intitulada O Povo Angolano resiste a novas provocações já avançava já no dia 28 de Julho com a versão dos agentes infiltrados nas FAPLA:

Um incidente verificado, neste fim-de-semana, entre forças do MPLA e soldados portugueses, veio pôr novamente na ordem dia, a questão da "neutralidade 
ativa” das tropas portuguesas. As explicações dadas pelo MPLA e pelo Comando português, são em parte contraditórias, mas alguma coisa já se compreende: elementos infiltrados (ou disfarçados) no MPLA terão provocado uma patrulha portuguesa e o Comando português em vez de propor uma comissão de inquérito conjunta, deu um prazo curtíssimo para receber as explicações do MPLA, sem as quais desencadearia uma "ação punitiva". A tática dos agentes infiltrados e consequente "ação punitiva”, é conhecida do Médio Oriente já há muito tempo. O cerco à Vila Alice com um aparato militar que o MPLA classifica de "estranho" e as vítimas provocadas pelas forças portuguesas (14 mortos e 22 feridos), em nada ajuda a clarificar a situação político-militar em Angola. ${ }^{14}$

Foi neste clima de instabilidade e suspeições que o Bureau Político do MPLA num comunicado de 29 de Julho, reafirmou a versão dos agentes infiltrados, "Na noite de sábado, 26 de Julho, uma patrulha das Forças Armadas Portuguesas foi intercetada e atacada por elementos infiltrados nas FAPLA, já identificados"15

O historiador militar, Brigadeiro Pezarat Correia, no livro Descolonização de Angola, A Joia da Coroa do Império Colonial Português, não hesitou em subscrever a versão dos agentes infiltrados e refere que

o MPLA não entregara os responsáveis nem os poderia entregar. Como mais tarde veio a ser denunciado, aquela ação não fora da responsabilidade do MPLA, mas sim dum grupo da FRA ${ }^{16}$, ou pelo menos sob o comando de seu antigo dirigente, que se fizera passar pelo MPLA para provocar um incidente entre este movimento e as tropas portuguesas. (1991:137)

O jornalista luso-angolano Artur Queirós no livro A Via Agreste da Liberdade, (1978) também subscreveu a versão dos agentes infiltrados do MPLA,

14 Jornal República, 28 de Julho de 1975, O Povo Angolano resiste a novas provocações, p. 1 e 10

15 Jornal O Século, 29 de Julho de 1975, Situação Angolana em equilíbrio instável, p.6

16 FRA, Frente de Resistência Angolana, organização da minoria branca, liderada pelo eng. Pompílio da Cruz, que tentou um golpe à rodesiana no dia 23 Outubro de 1974, imediatamente neutralizada pelas FAP. 
Um dos grupos, que já trabalhara para a FRA (Frente de Resistência Angolana) [...] era comandado por Toni Rodrigues, [...] Ngola Kabangu estudou com Rodrigues um processo de lançar as forças portuguesas contra o MPLA. [...] E o "esquadrão da morte " de Rodrigues recebeu ordens para atacar uma patrulha portuguesa. Assim, os seus homens fardaram-se de guerrilheiros das FAPLA e numa das ruas da Vila Alice, onde se encontrava o Comando Operacional de Luanda do MPLA, emboscaram um jeep das forças portuguesas. Depois de desarmarem os seus ocupantes mandaram-nos embora, tendo-os alvejado pelas costas.

Pompílio da Cruz dirigente da organização FRA, Frente de Resistência de Angola, que lutava por um protagonismo na cena política angolana, no livro Angola, os Vivos e os Mortos, confirma a versão dos agentes infiltrados avançada pelo MPLA e acusa um dos seus acólitos, um branco:

Foi a quadrilha de Toni Rodrigues [...] que, envergando fardas das FAPLA, apresaram uma viatura militar portuguesa, obrigando os seus ocupantes a despirem-se e ferindo um deles a tiro. Em desforço, tropas portuguesas, enganadas pelo ardil, atacaram a delegação do MPLA na Vila Alice. (1976:221)

Em que medida estas memórias em concorrência não se destinam, a rasurar a responsabilidade das FAPLA/MPLA no incidente?

\section{Masculinidades coloniais}

A reflexão teórica sobre este recorte histórico leva-nos a pensar no Ataque à Vila Alice à luz dos estudos de género e da teoria crítica feminista, seguindo o quadro teórico de Raewyn Connell conceptualizado no seu livro "Masculinities" (2011 [1995]), sobretudo o conceito de 'masculinididade hegemónica' sobre o qual, o antropólogo português Vale de 
Almeida também reflectiu:

Masculinidade entendida não como uma mera formulação cultural de um dado natural mas sim como um processo social, cultural e histórico, como uma estrutura de relações sociais [...] construidas através de relações de poder e socialmente dominantes. Masculinidade hegemónica como um elemento central de uma ordem de género, o patriarcado, na qual a masculinidade hegemónica define a inferioridade do feminino e de masculinidades subordinadas (Almeida, 2000).

A construção da masculinidade hegemónica é particularmente visível no campo militar e na guerra. Quando nos referimos a masculinidades militares estamos a identificar as masculinidades que se produzem nas instituições militares, um dos espaços mais importantes da demonstração de várias masculinidades e sobretudo da masculinidade hegemónica (Connell 1995, Enloe 2002, Higate 2005). Quando identificamos "masculinidades coloniais" estamos a falar de ordens de género, isto é, estamos a falar de relações sociais desiguais e também de relações de poder entre colonizadores e colonizados (Connell 1987, 1995, Almeida 1996, 2000, Butler 1990).

Embora a versão dos agentes infiltrados nas FAPLA domine as narrativas posteriores aos acontecimentos como vimos, o comando português em Angola parece não ter tido dúvidas quanto à responsabilidade das FAPLA/MPLA no incidente que vai desencadear o Ataque à Vila Alice na madrugada do dia 27 de Julho. No entanto, a escrita da história confronta-nos com memórias em conflito, memórias que não coincidem com os discursos oficiais. O MPLA tem todo um historial de "narrativas oficiais", destinadas a estabelecer legitimidades ou a desacreditar adversários, que têm sido postas em causa por memórias dissidentes e pelos historiadores. Neste artigo também é questionada, pelas fontes orais apresentadas, a versão dos "agentes infiltrados".

Mas será que o MPLA representava um perigo para as FAP ou para a comunidade branca? Num pequeno apontamento sobre os ingleses que abandonaram Angola na noite do 
incidente, veiculada pelo jornal República na mesma edição em que dá notícia do Ataque à Vila Alice, lê-se:

O Cônsul Geral Britânico, Stanley Croft, [...] declarou que a situação se estava a tornar cada vez mais perigosa, mas presentemente não havia qualquer movimento de vingança contra os brancos de Angola. Os brancos não são molestados mas tem havido massacres de negros feitos por negros". ${ }^{17}$

Esta afirmação é muito interessante porque expõe a situação em que se encontrava tanto a comunidade branca como as forças militares portuguesas; ambas estavam fora da luta pelo poder e tinham deixado de ter protagonismo político, ambas foram secundarizadas como atores sociais no meio daquele programa de desordem absoluta (Fanon, 2006[1961]:52) que foi a descolonização.

Obrigados a viver sob o signo da violência, o Major-General Heitor Almendra numa entrevista ao Coronel Manuel Amaro Bernardo no livro Memórias da Revolução em relação à política da neutralidade ativa, recordou: Foi-se tolerando a situação [...] até que aconteceu a Vila Alice... (2004:257-258)

Habituados à dominação colonial, à autoridade militar, confrontados com a perda repentina do privilégio, impedidos de dar continuidade a um imaginário nacional ligado à supremacia da raça branca ${ }^{18}$ e à missão civilizadora dos portugueses em África, a expressão Foi-se tolerando expõem uma situação de descontentamento com este "rito de passagem" de um poder colonial para um poder africano. O entrevistador continua,

\section{P: O que aconteceu nessa altura?}

17 Jornal República, 28 de Julho de 1975 p10, O Povo Angolano resiste a novas provocações

18 Raça como uma categoria com origem no senso comum, construída historicamente e que impregnou as relações sociais. Ou categoria socialmente construída no tempo e no espaço segundo ideologias dominantes. A branquidade como um constructo ideológico extremamente bem-sucedido do projeto modernista de colonização, é, por definição, um constructo do poder: os brancos, como grupo privilegiado, tomam a sua identidade como a norma e o padrão pelos quais os outros grupos são medidos. (Styen in Ware, 2004:115) 
R: A atuação foi levada a cabo por um pelotão de comandos e um pelotão de reconhecimento dos Dragões, [...] Como consequência do assalto das nossas tropas, julgo que morreram todos os militares do MPLA presentes... ”...

P: A partir dessa altura a tropa portuguesa conseguiu normalizar a situação?

R: Passámos a ser muito mais respeitados...(2004:257-258)

As FAP, habituadas à hegemonia e supremacia militar, intoxicadas pela ideologia colonial assente em discursos fundadores sobre a coragem do homem português e em valores de heroicidade e dignidade dos militares, tentaram com o ataque à Vila Alice recuperar o seu papel no tecido social e repor a ordem no meio de um universo que desabava à sua volta. O major-general Almendra realça na entrevista o facto de, após o Ataque, terem passado a ser muito mais respeitados.

O entrevistador tenta avaliar a "neutralidade" das FAP em relação à guerra entre o MPLA e a FNLA:

P: Entretanto decorriam aquelas guerras entre os movimentos...

R: [...] a guerra foi entre a FNLA e o MPLA [...]

P: Desculpe insistir, mas terá havido uma orientação de Lisboa, através dum telex, para ele [Gen. Silva Cardoso] apoiar o MPLA contra a FNLA...

R: Estava nas nossas mãos fazermos o que entendêssemos. Desrespeitar ordens de Lisboa, isso ocorria com muita frequência. Então alguém me podia violentar a fazer ações que considerava não dever efetuar?... (2004:257-258)

Sem negar o ressentimento deste ato de retaliação, convoco Albert Memmi em Retrato do Colonizado Precedido Pelo Retrato do Colonizador para situar este discurso de animosidade em relação às ordens da metrópole: 
O colonialista exige que a metrópole seja conservadora. [...] Mas o nacionalismo do colonialista é, na verdade, de natureza especial. [...]. Se a metrópole se tornasse democrática, por exemplo, a ponto de promover a igualdade de direitos até mesmo nas colônias, arriscar-se-ia também a abandonar as empresas coloniais. Semelhante transformação seria, para o colonialista, uma questão de [traição]. Compreende-se que seu nacionalismo vacile e que recuse reconhecer essa perigosa imagem da sua pátria. (1977[1957]:61-64).

Memmi escreveu estas palavras em 1957, palavras que anteciparam uma dos marcadores da descolonização em Angola, o ressentimento dos retornados em relação à metrópole, ressentimento que deixou marcas no tecido social português na póscolonialidade.

\section{Modulações raciais no ataque à Vila Alice}

Qual terá sido a verdadeira natureza da missão dos soldados portugueses na Vila Alice? O major-general Almendra responde a esta pergunta: Como consequência do assalto das nossas tropas, julgo que morreram todos os militares do MPLA presentes..." Será que a intenção era matar todos os militares do MPLA? Terá sido o Ataque à Vila Alice uma missão de represália motivada pela vingança? Mas que vingança foi essa?

\section{"A menina branca"}

Como terão os marcadores sociais de "raça", "sexo" e "género" funcionado nesta ação militar? Quem eram os militares do MPLA que o Major-General Almendra julga terem sido todos mortos?

Para Fanon a descolonização é sempre um fenómeno violento (2008[1961]: 51), durante a "Batalha por Luanda" as forças de guerrilha do MPLA que integravam instrutores cubanos e equipamento soviético, lutavam contra as forças da FNLA que integravam soldados e equipamento militar do exército zairense nas ruas da capital. À luz da teoria da luta revolucionária, que enquadrava o exército guerrilheiro do MPLA e no seguimento do 
apelo à Resistência Popular Generalizada feito por aquele movimento no dia 21 de Julho de 1975 (Júnior, 2007:38), quem tivesse cumprido a instrução militar num CIR, Centro de Instrução Revolucionário e fosse detentor de uma farda e arma combatia no mato ou na cidade e se fosse necessário combatia à margem da organização militar dos esquadrões das FAPLA e fora do enquadramento das estruturas do comando ${ }^{19}$.

\section{Testemunhos}

Sarlo, seguindo as pistas interpretativas que Benjamin abriu, diz-nos que os chamados "fatos da história são um "mito epistemológico" que reifica e anula a sua possivel verdade, encadeando-os num relato dirigido por alguma teleologia (2005:28), os testemunhos que vão ser apresentados têm como objetivo acrescentar outras versões ao relato da história.

Para registar e entender as diferentes versões do Ataque à Vila Alice a autora cruza o seu testemunho com o do oficial das FAP que foi ferido a 26 de Outubro de 2006 e cuja agressão esteve na origem da represália, António Manuel Rodrigues Guimarães, dado como morto na bibliografia consultada, e com o testemunho do General Almendra que comandou o Ataque à Vila Alice.

\section{O meu testemunho}

No dia 26 de Julho de 1975, próximo das 23 horas abandonei o cerco à FNLA que se encontrava entrincheirada na Fortaleza de São Pedro da Barra e regressei à Vila Alice, sede do comando operacional e constatei que nenhum responsável se encontrava presente no COL, nessa circunstância assumi as responsabilidades possiveis. Pouco tempo depois apresentou-se um grupo de quatro a cinco soldados das FAPLA, responsáveis pela barreira onde se deu o incidente já relatado com o oficial português. Os guerrilheiros chegaram visivelmente abalados e convencidos que tinham morto o oficial português. Segundo os seus depoimentos terão reagido de

19 No livro Forças Armadas Populares de Libertação de Angola, $1^{\circ}$ Exército Nacional (1975-1992), o historiador militar angolano Tenente-General Miguel Júnior, aponta que as forças guerrilheiras do MPLA teriam 20.000 homens em 1975. 
forma violenta à derrogação 'pretos de merda' e atirado no oficial. Os jovens eram todos negros e face à gravidade da história que narraram não tive outra alternativa senão pedir para entregarem as armas e dar-lhes voz de prisão. Quando mais tarde, telefonaram do Estado-Maior das FAP a intimar que os responsáveis do incidente fossem entregues, não pude responder à exigência porque, como guerrilheira, não estava investida de poderes para assumir essa responsabilidade.

Randall Kennedy no livro, The Stange Career of a Troublesome Word (2002), referindo-se à palavra nigger diz que é the nuclear bomb of racial epithets. A apropriação desta imagem para a língua portuguesa, permite dizer que 'preto de merda' é seguramente o insulto de ódio racial, a agressão verbal que mais emoções violentas provoca.

$\mathrm{O}$ ataque foi desencadeado de manhã cedo. Na guerra dos comunicados que se seguiram ao incidente da Vila Alice, no jornal $A$ Capital $^{20}$, pode-se ler:

... o Exército português encabeçado por comandos [...] terá desencadeado uma ação de repressão contra as instalações do Movimento Popular de Libertação de Angola, na Vila Alice, cercando-as com carros de combate e disparando selvaticamente com todo o tipo de armas incluindo lança-granadas-foguetes além de carros de combate sem o minimo respeito pelas dezenas de civis ali presentes e centenas de moradores da zona...

\section{O Dipositivo do ataque segundo o General Heitor Almendra}

O General Almendra descreveu ${ }^{21}$ na entrevista, um dispositivo militar poderoso composto por 2 Companhias de Cerco e duas Companhias de Ataque, 1 Pelotão de Comandos e um Pelotão de Reconhecimento dos Dragões com blindados, carros de combate, 5 autometralhadoras, lança-granadas-foguetes e armas pessoais ligeiras. $\mathrm{O}$ total dos efetivos terá variado entre 300 a 350 militares, o general não se recorda. No

20 no dia 28 de Julho, sob o título Trabalhadores de Luanda acusam Silva Cardoso

21 Entrevista realizada a18 de Maio de 2006 pela autora. 
mapeamento da tragédia, como já foi referido na citação do jornal Republica, 14 guerrilheiros e guerrilheiras do MPLA foram mortos e 22 feridos. Dois militares das FAP sofreram ferimentos.

Durante o Ataque a autora foi feita prisioneira e colocada em cima de um Unimogue ${ }^{22}$ donde escapou posteriormente com a ajuda do comandante da Segurança do MPLA, Onambwé e de um oficial das FAP que apareceram juntos no rescaldo da operação.

Trinta e um anos depois, no dia 18 de Maio de 2006, o agora General Heitor Almendra identificou-se numa entrevista realizada pela autora no âmbito de um trabalho académico, como o oficial das FAP responsável por a narradora deste trabalho não ter sido levada prisioneira para o QG das FAP. Segundo afirmou o General, quando chegou à Vila Alice com o comandante Onambwé viu uma menina branca fardada, rodeada de mortos e feridos, logo tomou a decisão de evitar que sofresse maiores humilhações ou até a morte à mão dos comandos e por isso ordenou à autora para descer do Unimogue. Quando perguntei ao General, durante a entrevista, porque não tinha sido atingida a resposta foi: Margarida, acha que algum comando ia ter coragem de atirar numa menina branca? Do testemunho do General Almendra, se intui que a intersecção entre raça, sexo e género terá salvado a autora de ser ferida, morta ou violentada. Mesmo na condição de "inimigo" a autora não escapou a ser uma "menina branca" e foi apropriada através da raça pelo grupo que supostamente a devia atacar. Os militares da FAP recusaram o agenciamento da identidade política da guerrilheira e sob o paradigma da masculinidade hegemónica e do manto do poder patriarcal protegeram a "menina branca". Serão raça, sexo e género inextricáveis um do outro? É possível, o sexo/género não salvou as minhas camaradas negras que foram atingidas. O protecionismo não se alargou a todas as mulheres presentes no teatro da guerra. Lembro-me de uma camarada que segurava nas mãos os intestinos após ter sido atingida por balas expansivas ${ }^{23}$ proibidas pelas Convenções de Haia e Genebra. Acho que este facto é suficiente para entender como estas categorias afetam a militarização das mulheres na guerra, como os papeis militares são genderizados ao mesmo tempo que ilustra a clivagem racial existente durante o ataque à Vila Alice.

22 Viatura militar

23 Balas cortadas na ponta. 


\section{Memória do outro lado da história}

\section{Testemunho do oficial das FAP António Manuel Rodrigues Guimarães ${ }^{24}$}

... No dia 26 de Julho de 1975 [...] já há noite -cerca das 22 horas saí do quartel em patrulhamento, sendo o [...] militar mais graduado, acompanhado por mais dois militares e o condutor da viatura. Perto da $7^{a}$ esquadra (estrada Catete - Luanda) fomos confrontados com mais um episódio que era já banal, de ter elementos fardados - farda essa que identificava qual o movimento a que pertenciam MPLA- a agredir um individuo de raça branca que não cheguei a identificar.

Ao ver tal situação paramos junto aos tais elementos, saí da viatura desarmado, deixando no jipe a G3 que sempre me acompanhava e, com mais dois camaradas perguntei quem era o comandante da patrulha e qual o motivo que os levava a agredir o senhor.

Respondeu-me um elemento que era ele que mandava e que o "branco" circulava sem salvo-conduto - vigorava o recolher obrigatório na altura e que resistira ao tentar fugir quando mandado parar. Questionei o homem que sofria a agressão do porquê de andar na rua sem autorização, tendo ele dito que morava perto e que vinha de casa da filha. Foi advertido para não voltar a cometer nova violação do recolher obrigatório e com a anuência do comandante da patrulha do MPLA foi mandado embora.

24 O oficial António Manuel Rodrigues Guimarães enviou este testemunho à autora pelo correio numa carta datada de 26 de outubro de 2006. Pertenceu à CPM 8241, com a patente de Alferes Miliciano e em resultado dos ferimentos que sofreu é portador de um grau de invalidez de $60 \%$. As narrativas dos antigos combatentes do exército colonial dão-no como morto na maior parte da bibliografia porque era essa a informação que circulava nos regimentos. Depois de um ano hospitalizado e várias intervenções cirúrgicas o oficial sobreviveu, aposentou-se do exército e hoje trabalha como engenheiro. 
Sankofa. Revista de História da África e de Estudos da Diáspora Africana Ano VI, NºXII,

Dezembro/2013

A já citada patrulha era constituida por 4 ou 5 elementos todos de raça negra. Sanado o incidente - quero referir que todo o diálogo decorreu debaixo de grande tensão e de alguns gritos dirigi-me para a viatura dando ordens aos meus camaradas para seguirmos com o patrulhamento e quando já me sentava na viatura, surgiu um desaguisado entre um soldado do MPLA com um camarada que me acompanhava e pressuponho eu por ter sido desautorizado, disparou uma rajada com a arma que empunhava para cima da viatura, tendo um dos projeteis atingido um camarada que já estava sentado no jipe numa perna e outro atingiu-me nas costas.

Como se depreende da descrição feita - a verdade nua e crua do que se passou -não fomos intercetados, nem desarmados como na altura se constou.

Através dos relatos de memória do oficial António Manuel Rodrigues Guimarães e da autora, relatos que remetem para memórias em conflito e que no entanto coincidem no que diz respeito à origem da agressão, ou seja o MPLA/FAPLA, o esforço de fixação da memória dos protagonistas da história contribui para questionar as versões dos agentes infiltrados no MPLA anteriormente apresentadas.

Esta narrativa demonstra também que os guerrilheiros das FAPLA na barreira, quando detiveram um colono agiram de acordo com a linha da identidade racial binária que separava brancos e negros e a partir de uma posição de poder que as armas conferiam. Memmi defende que a xenofobia e o racismo do colonizado contêm, seguramente, um imenso ressentimento e uma evidente negatividade (Memmi, 1977[1957]:114). Nas entrelinhas do testemunho do oficial, na expressão dos não-ditos é possível ler o conflito de ódio racial que os jovens guerrilheiros relataram - quero referir que todo o diálogo decorreu debaixo de grande tensão e de alguns gritos! R.W. Connell no livro Masculinities, situa o papel das masculinidades coloniais dominantes e subordinadas e escreve que Paul Hoch in White Hero, Black Beast pointed to the pervasiveness of racial imagery in [...] discourses of masculinity. White fears of black men's violence have a long history in colonial and postcolonial situations, Black fears of white men's terrorism, founded in the history of colonialism, have a continuing basis in white's men's control of police, courts and prisons ... (Connell 2011[1995]:75) 


\section{Concluindo}

Este ataque ilustra particularmente a clivagem racial que existia na sociedade colonial e que se revelou durante o processo de descolonização através de incidentes de provocação mútua. Para Memmi é significativo que o racismo faça parte de todos os colonialismos, em todas as latitudes. Não é uma coincidência: o racismo resume e simboliza a relação fundamental que une colonialista e colonizado. (Memmi, 1977[1957]:68).

Segundo Heimer, quem já se debruçou sobre o processo de colonização em África não pode ignorar que a dominação portuguesa tinha uma forte componente racial. [...] atrás da "cortina de fumo" de uma ideologia "luso-tropical", as relações sociais eram gradualmente, mas não constitutivamente, diferentes do que em qualquer outra parte do continente. (Heimer, 1978:20)

A maior parte dos estudos contemporâneos é unânime em contrariar alguns dos mitos enraizados na memória coletiva portuguesa como o da excecionalidade de um império não-racializado ou ainda a fábula da colonização ter sido "branda". Por muito que os historiadores e cientistas sociais repitam que, ao contrário do que a "cartilha colonial" publicitava, da interação entre portugueses e africanos não parece ter emergido uma sociedade menos racista do que as que foram projetadas por outros Impérios europeus, esta análise não consegue contaminar o discurso publico e do senso-comum talvez porque como Memmi nota o opressor precisa de sair inocente...(Memmi, 1977[1957]:73).

António de Almeida Santos no segundo volume do seu livro Quase Memórias refere um episódio elucidativo da cultura patriarcal e do "olhar" colonial que o Alto-Comissário e o Gen. Almendra derramavam sobre os africanos e sobre os exércitos dos movimentos de libertação,

No regresso ao Palácio do Governo, de novo por entre a sinfonia de tiros [...] deparou-se-me um espetáculo insólito. Um oficial português, devidamente fardado, 
numa pequena praça, esbofeteava dois africanos" [...] Quando cheguei ao palácio do governo referi o facto ao alto-comissário, exprimindo a minha estupefação. Mas o alto-comissário Banalizou: - Ah! Isso é o Almendra! [...] Quando recebo a queixa de uma querela entre membros dos movimentos [...] mando o Almendra. [...] $O$ Almendra vai desarmado, ouve as razões de cada parte e arbitra. Se a arbitragem é acatada, o conflito morre. Se não, aplica os métodos que os pais costumam usar com os filhos. Quando é preciso sai tabefe..." ao que o Coronel Almendra retorquiu mais tarde: “- Sabe, [...] um militar desarmado infunde mais respeito do que um pelotão carregado de armas. E os velhos métodos, por vezes, ainda são melhores que os modernos! (1986:181)

Os "velhos métodos", os tabefes paternalistas eram os métodos utilizados pelos paradigmas das masculinidades coloniais que infantilizavam o negro, o consideravam imaturo, ridicularizavam e inferiorizavam o "Outro". Esta narrativa, para usar palavras de Mark Sabine expõe a "emasculação" do "outro" africano. Expõe o papel do [white hero] que assenta numa fantasia da hipermasculinidade do colonizador português, o qual [...] dissemina “civilização” europeia na "barbárie” africana. (Sabine, 2010:189)

As FAP ao serem obrigadas a renunciar ao poder e conscientes de que tinham perdido o estatuto de dominadores protegeram e asseguraram o êxodo da comunidade branca em segurança como convinha a um exército colonial. Quando reagiram no terreno, fizeram-no em função de 'masculinidades coloniais' feridas, e ancoradas na identidade racial branca. Para o exército português mergulhado num tecido ideológico onde a heroicidade das suas forças não podia ser posta em causa por um exército guerrilheiro de 'bárbaros' negros, exército que sempre foi olhado e sentido como 'inferior' - o MPLA, o impensável aconteceu e uma lição exemplar foi dada aos culpados. Os mortos e os feridos são testemunho da brutalidade do Ataque. Através da violência foi imposta a supremacia militar num contexto racializado.

As declarações do general Almendra enquadram o ataque à Vila Alice numa tomada de decisão política independente do poder central, que a demissão do Alto-Comissário Silva 
Cardoso três dias depois do ataque parece confirmar, portanto é neste contexto que tem que ser enquadrada a legitimidade das FAP para desencadearem a ação punitiva. - Estava nas nossas mãos fazermos o que entendêssemos! ou seja a emasculação do "outro" africano através das masculinidades coloniais e da violência direta. Cem dias depois Portugal abandonou Angola sem transmitir a soberania aos novos governantes, aos 'bárbaros' negros no dia da Independência Nacional, 11 de Novembro de 1975. - O que seria de nós sem os bárbaros $?^{25}$

\section{Referência bibliográfica}

ADAM, Yussuf, 2005, Escapar aos dentes do crocodilo e cair na boca do leopardo. Trajectoria de Moçambique pós-colonial (1975-1990), Maputo, Promédia

ALMEIDA, Miguel Vale de, 2000, Senhores de Si, Uma Interpretação Antropológica da Masculinidade, Lisboa, Fim de Século

ANZALDÚA, Gloria, 1987, Borderlands/La Frontera: The New Mestiza, San Francisco, Aunt Lute Books

BERNARDO, Manuel A., 2004, Memórias da Revolução, Lisboa, Editora Prefácio

CARDOSO, Silva, 2000, Angola, Anatomia de uma tragédia, Lisboa, Oficina do Livro

CONNELL, R.W., 2011[1995], Masculinities, Cambridge, Polity

CORREIA, Pezarat, 1991, Descolonização de Angola, A Joia da Coroa do Império Colonial Português, Mem Martins, Editorial Inquérito

CRUZ, Pompílio da, 1976, Angola, Os Vivos e os Mortos, Lisboa, Editorial Intervenção

DELORY-MOMBERGER, C., 2006, Fotobiografia e formação de si. in Souza, Elizeu Clementino, orgs, Tempos, narrativas e ficções: a invenção de si. Porto Alegre, Salvador, Edipucrs e Eduneb, p. 104-117

FANON, Frantz, 2006[1961], Os Condenados da Terra, Salvador, Juiz de Fora, UFJF

FANON, Frantz, 2008[1952], Pele Negra, Máscaras Brancas, Salvador, EDUFBA

GOFF, Jacques le (2006), História e Memória, Campinas, Editora Unicamp

HARAWAY, D., 1991[1988], Situated Knowledges: The Science Question in Feminism and the Privilege of Partial Perspective, in Haraway, D. (ed.). Symians, Cyborgs and Women: the Reinvention of Nature, NY, Routledge, p. 183-202

25 Referência a "Esperando os Bárbaros" (1904) in Poemas de Konstantinos Kavafis, (trad., estudo e notas de Isís Borges da Fonseca), S. Paulo, Ed. Odysseus, 2006, pp. 65-67. K.Kavafis poeta de Alexandria que trouxe a Grécia para África "E agora que será de nós sem bárbaros? Esses homens eram uma solução.” 
HEIMER, Franz Wihlem, 1978, O Processo de Descolonização de Angola, 1974-1976, Lisboa, A Regra do Jogo

JUNIOR, Miguel, 2007, Forças Armadas Populares de Libertação de Angola, $1^{\circ}$ Exército Nacional (1975-1992), Lisboa, Prefácio

MATA, Inocência, 2011, Uma intensa disseminação: a África como locus na literatura portuguesa, Letras com Vida - Literatura Cultura e Arte. nº 3, p.132 a 140

MEMMI, Albert, 1977[1957], Retrato do Colonizado Precedido Pelo Retrato do Colonizador, Rio de Janeiro, Paz e Terra

MESSIANT, C., 1997, Em Angola até o passado é imprevisível: A experiência de uma investigação sobre o nacionalismo angolano e, em particular, o MPLA: Fontes, crítica, necessidades atuais de investigação, in Atas do II Seminário Internacional sobre a História de Angola: Construindo o passado angolano: as fontes e a sua interpretação, Lisboa, Comissão Nacional para as Comemorações dos Descobrimentos Portugueses, p.803-859

QUEIRÓS, Artur, 1978, Angola, do 25 de Abril ao 11 de Novembro, a Via Agreste da Liberdade, Lisboa, Ulmeiro

Rossi, Paolo (2003), El pasado, la memoria, el ovildo, Buenos Aires, Nueva Visión

Sabine, Mark, 2010, Nós matámos o cão-tinhoso: A emasculação de África e a crise do patriarca negro, Revista Atlântica, $\mathrm{n}^{\mathrm{o}}$ 17, p. 12 a 35

SANTOS, António de Almeida, 1986, Quase Memórias, $2^{\circ}$ Vol., Lisboa, Casa das Letras

SARLO, Beatriz, 2007, Tempo passado, cultura da memória e guinada subjetiva. Belo Horizonte, UFMG e Companhia das Letras.

TALI, Jean-Michel M., 2001, Dissidências e Poder de Estado, o MPLA Perante Si Próprio (1962-1977), Ensaio de História Política, II ${ }^{\circ}$ vol. 1974-1977, Luanda, Nzila

WARE, Vron org., 2004, Branquidade, Identidade Branca e Multiculturalismo, RJ, Garamond

\section{SIGLAS E ABREVIATURAS}

CIR, Centro de Instrução Revolucionária

COL, Comando Operacional de Luanda

CPPA, Corpo de Polícia Popular de Angola

FAP, Forças Armadas Portuguesas

FAPLA, Forças Armadas Populares de Libertação de Angola

FNLA, Frente Nacional de Libertação de Angola 
Sankofa. Revista de História da África e de Estudos da Diáspora Africana Ano VI, NºXI, Dezembro/2013

FRA, Frente de Resistência de Angola

MFA, Movimento das Forças Armadas

NT, Nossas Tropas

QG, Quartel-general

UNITA, União Nacional para a Independência Total de Angola 